\title{
Análise de Projeto Urbano a partir de parâmetros urbanos sustentáveis: alteração morfológica de Copacabana e algumas de suas consequências climáticas (1930-1950-2010)
}

\author{
Analysis of Urban Design from sustainable urban parameters: \\ Copacabana's morphological changes and some of their \\ consequences on climate (1930-1950-2010)
}

Gisele Silva Barbosa ${ }^{[0]}$, Angela Maria Gabriella Rossi ${ }^{[b]}$, Patricia Regina Chaves Drach ${ }^{[c]}$

[a] Doutora em Urbanismo pela Universidade Federal do Rio de Janeiro (UFRJ), professora do Programa de

Pós-Graduação em Engenharia Urbana da Universidade Federal do Rio de Janeiro (UFRJ), Rio de Janeiro, RJ - Brasil, e-mail: giselebarbosa@poli.ufrj.br

[b] Doutora em Engenharia de Produção pela Universidade Federal do Rio de Janeiro (COPPE/UFRJ), com pós-doutorado na Escuela de Ingenieros de Caminos, Canales y Puertos da Universidad Politécnica de Madrid, professora do Programa de Pós-Graduação em Engenharia Urbana da Universidade Federal do Rio de Janeiro (UFRJ), Rio de Janeiro, RJ - Brasil, e-mail: gabriella.rossi@poli.ufrj.br

[c] Doutora em Modelagem Computacional pelo Laboratório Nacional de Computação Científica (LNCC/MCTI), com pós-doutorado na School of Engineering and Built Environment, Glasgow Caledonian University e pesquisadora do CNPq, Rio de Janeiro, RJ - Brasil, e-mail: patrícia.drach@gmail.com

\section{Resumo}

Durante as últimas décadas, sente-se a mudança climática em diversas regiões do mundo. Em muitas cidades, o aumento da temperatura é intensificado por projetos urbanos cujas morfologias dificultam ou canalizam a ventilação, aumentam as áreas de absorção e as de reflexão da luz solar. Consequentemente, o microclima local é alterado e o aumento da temperatura é sentido mais intensamente pela população. A forma urbana e a tipologia das edificações podem afetar o microclima local, criando ou evitando, por exemplo, o efeito estufa. Este artigo tem como propósito estudar as mudanças da morfologia e da tipologia do bairro de Copacabana, desde 1930, que possam ter levado a essas alterações. Foram utilizados resultados de trabalhos anteriores nos quais foram realizadas simulações virtuais de ventilação e temperatura, assim como simulações físicas com maquetes de um trecho do bairro de Copacabana em túnel de vento, verificando mudanças na ventilação e na temperatura local nos últimos 80 anos. Neste trabalho, utilizaram-se os dados das simulações confrontados com as morfologias do bairro nas décadas de 1930, 1950 e 2010, de forma a verificar a influência das mudanças morfológicas e tipológicas nos resultados obtidos. Para isso, foram consideradas categorias analíticas descritas na literatura para análise de projetos urbanos sustentáveis. Confirmaram-se as hipóteses iniciais, de que as alterações morfológicas em um projeto urbano podem ter consequências climáticas diretas no ambiente, conforme foi o aso dessa área de Copacabana, onde houve aumento considerável da temperatura e alteração nos fluxos de ventilação.

Palavras-chave: Projeto urbano. Morfologia urbana. Alteração de microclima. Rio de Janeiro. 


\begin{abstract}
During the last decades climate change is being felt in many parts of the world. In many cities, the temperature rise is intensified by urban projects which morphologies difficult ventilation, increase absorption areas and areas of reflection of sunlight. Consequently, the local microclimate is altered and the temperature rise is felt more intensely by the population. Urban form and typology of buildings can affect local microclimate creating or avoiding, for example, the greenhouse effect. This article aims to study the changes of morphology and typology of Copacabana since 1930 that might have led to these changes. Results from previous studies were used. These studies were done using virtual simulations of ventilation and temperature, as well as physical simulations with models of parts of Copacabana in a tunnel of wind, verifying changes in ventilation and local temperature in the past 80 years. In this study were used data from simulations confronted with the morphologies of the neighborhood in the 1930s, 1950 and 2010, in order to check the influence of the typological and morphological changes in the results obtained. For this study were considered analytic categories described in the literature for the analysis of sustainable urban projects. The study confirmed the initial hypotheses in which the morphological changes in an urban project can have direct consequences on the environment, as was the case of Copacabana area in which there was a considerable rise in temperature and a change in the pattern of ventilation.
\end{abstract}

Keywords: Urban design. Urban morphology. Change of microclimate. Rio de Janeiro.

\section{Introdução}

Nas últimas décadas, muitas cidades têm passado por um acelerado processo de urbanização. No ano de 2007, a população urbana mundial superou em quantidade a população rural. No Brasil, esse quadro é ainda mais notório. De acordo com o Censo (INSTITUTO BRASILEIRO DE GEOGRAFIA E ESTATÍSTICA, 2010), a população urbana brasileira representa cerca de $84 \%$ da população total. Consequentemente, as cidades estão em constante mudança, alterando suas configurações físicas para atender às necessidades desse contingente populacional.

Para atender ao aumento populacional e às necessidades urbanas como moradia, trabalho, lazer, muitos estudiosos da atualidade defendem a ideia de compactação das cidades, seja adensando áreas já urbanizadas ou expandindo a cidade existente. Por exemplo, muitas intervenções e legislações optam por adensar áreas já urbanizadas, aumentando gabaritos e diminuindo áreas livres.

Além de uma cidade compacta, a grande maioria dos estudos atuais defende a ideia de cidade mista, onde as diversas atividades da vida cotidiana são desenvolvidas em espaços reduzidos e compartilhados.
Os conceitos de cidade compacta e cidade mista têm sido amplamente defendidos como princípios de sustentabilidade urbana, e ambos são determinados através do processo de desenho urbano, na definição da morfologia adequada para tais fins.

A contribuição para a sustentabilidade que uma cidade compacta e mista pode ocasionar traduz-se principalmente na diminuição das distâncias e, consequentemente, na diminuição do uso do automóvel.

0 bairro de Copacabana, estudado neste artigo, passou por um processo de adensamento ainda na década de 1950, impulsionado, principalmente, pelo crescente interesse imobiliário. Atualmente, Copacabana é um dos bairros mais densos do Rio de Janeiro e possui uma estrutura física relativamente constante, constituída por edifícios com cerca de 12 andares e algumas torres mais altas na avenida principal do bairro. Além de possuir uma malha viária com vias paralelas à orla mais largas e vias transversais mais estreitas, o bairro possui diferentes usos, como comércio, habitação, lazer, escritórios.

A morfologia atual de Copacabana coopera para muitos pontos positivos, como a redução das distâncias, a possibilidade de implantação de transportes de massa como o metrô, a diminuição dos custos de infraestrutura, dentre outros. No entanto, esse 
adensamento também contribui para a ocorrência de diversos problemas urbanos relacionados à iluminação natural, à ventilação e até à própria mobilidade.

Principalmente por estar localizada em uma região tropical, a morfologia de Copacabana interfere diretamente no conforto térmico local. A partir de estudos anteriores se verificou, por meio de simulação computacional em um bairro da cidade de Niterói, que a temperatura, medida no mês de janeiro, sofreu um aumento entre $3{ }^{\circ} \mathrm{C} \mathrm{e} 9{ }^{\circ} \mathrm{C}$ no período de adensamento desse bairro (BARBOSA; DRACH; CORBELLA, 2010). No caso específico de Copacabana, a partir de simulações desenvolvidas no programa ENVI-met também foi verificado um aumento da temperatura de cerca de $3{ }^{\circ} \mathrm{C}$ entre os períodos de 1930, 1950 e 2010. Através de estudos das intervenções físicas no bairro ao longo dessas décadas, foi verificada uma mudança significativa na morfologia, e esse fator pode ser o principal responsável pelas alterações da temperatura e dos ventos. Dessa forma, este artigo tem como objetivo verificar aspectos da morfologia do bairro que podem ter contribuído para a alteração do microclima.

\section{Sustentabilidade urbana e projeto urbano}

Nos dias atuais, não são concebíveis os estudos urbanos sem a reflexão e a análise da sustentabilidade urbana. Apesar de muito discutido, o termo sustentabilidade não possui uma definição única, mas é aceito por diferentes setores da sociedade. Existem indefinições tanto sobre a origem do termo quanto sobre seu significado. Utilizado com algum senso comum, o conceito de sustentabilidade, na ausência de definição precisa, adquire vários sentidos, algumas vezes contraditórios, tornando comum sua utilização em discursos e ações diferentes. Sachs (1997) alerta para a manipulação do conceito de acordo com os diferentes interesses políticos e econômicos de cada sociedade. Para o autor, o termo sustentabilidade aglutina amigos e inimigos e gira em torno de uma variedade de definições e interesses.

No estudo das cidades, os significados conflitantes do termo sustentabilidade também estão presentes. No entanto, o fator prático e mensurável do projeto urbano pode trazer respostas mais claras e tangíveis ao termo. Para este artigo, que preza por uma avaliação quantitativa e qualitativa de um determinado território, é possível verificar características de projeto que não condizem com parâmetros de sustentabilidade urbana, principalmente no que tange à morfologia.

Os parâmetros de sustentabilidade urbana ainda são incertos, principalmente pela dificuldade em mensurar parâmetros intangíveis, como as necessidades da sociedade atual ou das sociedades futuras. No entanto, alguns termos são comuns nos estudos urbanos que incluem a sustentabilidade, como metabolismo urbano, regionalismo, tecnologias ambientais, dentre outros. Além disso, algumas ações já são comumente aceitas como sustentáveis, como a substituição da matriz energética para fontes de energias renováveis, o incentivo ao transporte público e o adensamento controlado do território.

A expressão metabolismo urbano considera que a meta ideal seria um processo com ciclo metabólico "fechado" no qual praticamente tudo fosse reutilizado e reciclado, com uma retirada de novos recursos do meio ambiente bastante reduzida e, em consequência, com uma geração de resíduos também baixa. Ciclos urbanos "fechados" que atendam às necessidades humanas atuais, sem comprometer as necessidades futuras, considerando as diferentes escalas locais e globais e a viabilidade econômica e os limites dos recursos naturais seriam um sistema urbano sustentável ideal. Dessa forma, a cidade pode ser compreendida como um ecossistema, à medida que engloba um conjunto de organismos que interagem em um mesmo habitat (FARR, 2008).

Contudo, a sustentabilidade das cidades não se refere apenas às questões ecológicas, mas também à qualidade de vida e à convivência em sociedade. Nesse aspecto, as questões ambientais são muitas vezes as mais fáceis de serem reconhecidas na busca por cidades sustentáveis, por serem mais facilmente mensuráveis. Os condicionantes sociais, econômicos, culturais e políticos, no entanto, são mais complexos e difíceis de quantificar.

No âmbito de alcance do urbanista e da engenharia urbana, o projeto urbano é um dos principais instrumentos de atuação em prol da sustentabilidade urbana. Toda e qualquer intervenção ou projeto urbano atua diretamente tanto em questões espaciais quanto em questões políticas e sociais. Entendese por projeto urbano ou design urbano ou ainda, 
traduzindo para o idioma português, o desenho urbano como "campo disciplinar que trata da dimensão físico-espacial da cidade" (DEL RIO, 1990) ou "a construção do lugar - o ambiente construído que preenche nossos corpos e espíritos e permite nossa existência enquanto indivíduos e seres sociais" (DEL RIO; SIEMBIEDA, 2013).

Sendo assim, o ambiente urbano é onde ocorrem as interações entre habitantes em um mesmo espaço e sua forma é o suporte físico para a realização das atividades cotidianas.

\section{Morfologia urbana e sustentabilidade}

A morfologia urbana é um dos fatores determinantes na busca pela sustentabilidade urbana. As definições e alterações morfológicas influenciam diretamente a qualidade dos espaços, a mobilidade e o conforto bioclimático local. 0 desempenho ambiental e social dos espaços urbanos pode ser melhorado a partir das características físicas da área, como suas conformações geométricas, desde seu traçado viário até as geometrias das edificações, a presença de vegetação, os cheios e vazios criados pela conformação do espaço, dentre outros (BARBOSA, 2013).

Neste artigo, assumem-se a palavra morfologia para fazer referência à forma urbana e a palavra tipologia para fazer referência à forma das edificações. Tanto uma como a outra interferem no microclima local, amplificando ou reduzindo os efeitos climáticos e, por vezes, contribuindo para o efeito estufa.

A morfologia define o traçado urbano que, independente de ser sinuoso, radial ou retilíneo, influirá nos aspectos relativos ao microclima, já mencionados. Portanto, a adequação da morfologia urbana ao clima local é fator fundamental no desenvolvimento de espaços de conforto. A partir da morfologia, define-se a compactação ou dispersão da cidade, decidindo-se sobre a distância entre as habitações e áreas de trabalho, sobre a largura de pistas de rolagem e calçadas do sistema viário, sobre a concentração dos serviços em um único centro ou a dispersão em diversos núcleos de bairro, e sobre outras definições físicas do projeto. A tipologia cabe ao poder público no que tange às leis de zoneamento que definem afastamentos e alturas das edificações, mas também cabe aos projetistas quanto às características formais do projeto.
Nesse caso, o que mais influencia o microclima urbano são as leis de zoneamento.

A morfologia da urbe pode influenciar tanto as relações humanas que ocorrem na cidade quanto os gastos de energia e produção de insumos. A forma urbana pode propiciar diferentes tipos de uso. Um ambiente com pistas de rolamento e passeios mais largos podem proporcionar uma região mais adequada para o comércio. No entanto, também é um conceito de cidade sustentável o uso misto. Um bairro misto, com comércio, lazer, áreas empresariais e residenciais, auxilia na diminuição do uso do automóvel, aumenta a sensação de segurança, tanto no período noturno quanto no diurno, e facilita a proximidade dos indivíduos (BARBOSA, 2013).

A qualidade e o modo como são feitas as trocas do meio urbano com o meio ambiente são determinados pelo espaço urbano, por meio de sua forma física e disposição das suas partes, em uma compreensão sistêmica (ANDRADE; GOMES; BORGES, 2008). 0 uso racional dos recursos naturais e a organização eficiente do transporte público dependem da forma urbana. Sendo assim, é de responsabilidade dos projetistas estabelecer estratégias e princípios norteadores referentes à morfologia e às infraestruturas, propiciando ambientes urbanos com proximidade dos elementos estruturais relacionados à forma física. A forma ideal provavelmente não será alcançada, mas alguns princípios podem ser orientadores para projetos urbanos mais sustentáveis.

A forma urbana influencia diretamente a sustentabilidade, tanto das funções quanto das atividades realizadas nas cidades. Os dois principais exemplos são a estrutura viária e de transporte, incluindo o tecido urbano, e o uso do solo (LEMOS, 2010). Esses dois exemplos, inclusive, são os mais utilizados na defesa da forma compacta como alternativa para as cidades sustentáveis.

A forma urbana também influencia diretamente o consumo de energia local, diretamente ligado à densidade populacional e construtiva. Dessa forma, a relação entre espaços livres e espaços construídos, a presença ou não de vegetação nos espaços abertos, a orientação solar das vias e o gabarito e os afastamentos das edificações no tecido urbano, as dimensões das vias e até mesmo os materiais utilizados na construção das edificações interferem 
na qualidade urbana e nas atividades realizadas na urbe, como deslocamentos e distribuição dos usos (ROSSI; BARBOSA; ARAGÃO, 2012).

Esse último parâmetro, a distribuição dos usos, também é um fator importante para o projeto urbano. $\mathrm{O}$ uso misto nas áreas urbanas é um tema menos controverso dentre os estudiosos. Apesar de muitas cidades terem sido construídas nos moldes modernistas de zoneamento, atualmente a grande maioria dos planejadores e projetistas urbanos defende o uso misto.

0 zoneamento tende a evitar a complexidade urbana, reduzindo as cidades em divisões simples, mais fáceis de administrar do ponto de vista legal e político, mas ao mesmo tempo impede uma relação mais saudável do homem com o meio e com seu semelhante. Nos territórios divididos por zonas, uma pessoa tem dificuldade, por exemplo, de usufruir de um ambiente natural em horário de almoço, pois as áreas verdes estão distantes das áreas de trabalho. Além disso, as grandes vias de tráfego necessárias para interligar esses ambientes setorizados dificultam os acessos a pé ou de bicicleta a bairros vizinhos.

Normalmente, as áreas de trabalho estão localizadas em centros urbanos que ficam desertos e perigosos durante a noite, enquanto a habitação e o lazer estão presentes em bairros mais afastados, conectados ao centro comercial por autopistas. O impacto ambiental causado por esse zoneamento é muito maior do que o impacto causado por planejamentos nos quais o trabalho, o lazer e a habitação se integram em ambientes próximos e muitas vezes compartilhados.

É a morfologia urbana que também influencia a dinâmica urbana, especialmente a mobilidade. O fluxo de pedestres e carros organiza a hierarquia das vias e a forma como esse sistema viário é projetado pode ajudar ou dificultar o uso de transportes públicos e alternativos. Também traz reflexos para a morfologia a intenção de diminuir as distâncias entre as atividades, pois uma das soluções projetuais é aumentar o uso misto em ambientes urbanos para também minimizar o consumo de energia. Para Girardet (2001), o planejamento de uma cidade mista e diversificada pode reduzir a poluição e o consumo excessivo de energia. Girardet (2001) também destaca a importância de projetos urbanos que privilegiam bairros com centros comerciais capazes de suprir as necessidades da população daquela região (cidade polinucleada).

Outra questão morfológica levantada por Ian Bentley et al. (1999) é o conceito de permeabilidade para o projeto urbano. Somente locais acessíveis podem ser desfrutados. A possibilidade de alcançar locais por caminhos diferentes e a qualidade desses acessos são essenciais para trazer vitalidade para a área urbana. Além disso, as normas de uso do solo urbano também influenciam para estabelecer um conjunto harmônico de vias e a permeabilidade entre as edificações. As definições legislativas sobre o uso do solo também influenciam a temperatura e a ventilação local. Edificações muito altas e próximas podem criar túneis de vento ou barreiras e, ainda, impedir a entrada da iluminação solar. No entanto, as áreas de sombra em países tropicais têm pouca influência na diminuição da temperatura.

A morfologia urbana também pode contribuir para a integração entre o natural e o ambiente construído, melhorando o contexto urbano através da introdução de vegetação na área urbana e facilitando a criação de corredores naturais.

A tipologia das edificações, por sua vez, também terá grande importância quanto ao uso da iluminação natural e da ventilação, contribuindo para o uso racional da energia elétrica. Os edifícios são um dos principais fatores responsáveis pelo consumo de energia, e suas tipologias podem reduzir o consumo quando esses edifícios são projetados com princípios bioclimáticos (CORBELLA; YANNAS, 2003).

0 planejamento de bairros e até de cidades inteiras pode ser baseado em parâmetros urbanos sustentáveis com morfologias que auxiliem na aproximação "saudável" da cidade com a natureza. Projetos urbanos que propiciem, por exemplo, o acesso irrestrito aos bens e espaços públicos, aumentando também a interação entre indivíduos de classes sociais distintas, podem indicar um caminho na busca pela sustentabilidade urbana.

\section{Morfologia Urbana e sua relação com o microclima}

Como mencionado anteriormente, nas últimas décadas, uma linha de estudos sobre o projeto urbano sustentável vem sendo bastante difundida na área acadêmica e, consequentemente, modificando planejamentos urbanos de novos bairros e cidades. Esse 
pensamento, defendido por autores como Girardet (2001) e Nobre (2004), dentre muitos outros, apontam para a associação de três parâmetros urbanos para se alcançar projetos urbanos sustentáveis: a densidade, a diversidade e o transporte público. Além desses três parâmetros, é importante salientar um quarto parâmetro apontado por Cervero e Kockelman (1997) nos estudos específicos sobre transporte urbano sustentável que é o design. 0 termo deve ser compreendido como o projeto propriamente dito, e consequentemente, é o que rege os demais parâmetros. É o projeto que define a forma urbana, os acessos, os limites, dentre outros parâmetros urbanos. Apesar de o urbanista não interferir diretamente na escolha dos usuários que usufruirão determinado território, a construção de espaços diversificados incentiva a diversidade cultural e social.

Além disso, o primeiro parâmetro, a densidade, merece uma discussão mais ampla, pois o adensamento deve ter um limite, que vai variar com as características do lugar. Nas últimas décadas, o discurso do adensamento urbano como uma proposta promissora para a sustentabilidade tem prevalecido, principalmente, nos fóruns e estudos dos países do Hemisfério Norte. A ideia principal da compactação urbana é construir cidades com deslocamentos menores. No entanto, um dos princípios de sustentabilidade é que cada projeto seja feito para um determinado espaço e época, e nem sempre a compactação é a solução mais adequada. Para Mike Jenks e Nicola Dempsey (2005, p. 39):

Densidade urbana é citada como uma defensora potencial de sustentabilidade, oferecendo oportunidades para o aumento da economia de energia e redução das necessidades de viagens. 0 que falta é a questão política de como essa estratégia poderia ser implementada. Neste contexto, tem havido muito menos consideração das políticas sociais, econômicas e culturais que fundamentam o processo pelo qual a sustentabilidade urbana poderia ser alcançada.

Para os autores, a densidade, se considerada isoladamente, também é problemática. No entanto, também pode ser utilizada como um instrumento como tantos outros na busca da sustentabilidade urbana (JENKS; DEMPSEY, 2005). 0 adensamento não pode ser visto como uma solução coerente para todas as regiões. De acordo com Nobre (2004), um estudo realizado pelo Banco do Trabalhador da Venezuela demonstra que o gráfico entre a necessidade de infraestrutura e a densidade populacional é uma parábola cujo ponto de otimização ficaria em torno de mil habitantes por hectare. Rodrigues (1986), num estudo realizado para a realidade brasileira, afirma que uma densidade menor que cem habitantes por hectare inviabiliza a presença de serviços e infraestrutura; já uma densidade superior a 1,5 mil habitantes por hectare gera problemas sociais, econômicos e ambientais, como é o caso de alguns bairros do Rio de Janeiro. Copacabana, por exemplo, possui problemas com a diminuição da velocidade e da canalização dos ventos nas vias mais largas, aumentando a temperatura nos edifícios e na escala do pedestre (CORBELLA; YANNAS, 2003).

Do ponto de vista bioclimático, nos trópicos úmidos, a cidade compacta propicia a formação de ilhas de calor, com o consequente aumento do consumo de energia elétrica e com o uso excessivo de ar condicionado e produção de poluição.

Este texto se coloca dentro das linhas de pensamento que defendem a instalação de um limite para o crescimento da urbe, com o incentivo às pequenas e médias cidades e à criação de outras novas (CORBELLA, 1998). Tais ações podem trazer para uma cidade densa todas as vantagens citadas aqui, sem os problemas gerados pela macroescala, além de promover melhor participação da sociedade nas decisões políticas. Uma cidade menor pode ser socialmente diversificada, com a multiplicação das diferentes atividades sociais e econômicas e a uma integração mais fácil da sociedade (MOORE, 1998).

Além disso, outro estudo apresentado recentemente apresenta uma relação considerável entre a temperatura local, a ventilação e a densidade (BARBOSA; DRACH; CORBELLA, 2010). Nesse estudo, demonstrou-se, por simulação computacional, que o aumento da densidade aumenta consideravelmente a temperatura, principalmente nos países dos trópicos. Sabe-se que a introdução de novos elementos ou a alteração dos existentes na malha urbana é capaz de alterar drasticamente o microclima e produzir resultados de desconforto ambiental. A simulação computacional introduz a possibilidade de avaliar alterações previamente e selecionar aquelas mais adequadas ao conjunto. Chegou a ser 
constatado um aumento de até $9^{\circ} \mathrm{C}$, quando comparados um bairro real pouco adensado e uma simulação desse mesmo espaço adensado por simulação computacional, com as mesmas condições viárias e os mesmos materiais construtivos. Já em uma cidade da Alemanha, essa variação não passou de $2{ }^{\circ} \mathrm{C}$, constatando-se que em países do Hemisfério Norte esse acréscimo não é negativo.

Acredita-se que as características climáticas locais são determinantes para as decisões do projeto urbano, e apesar das recomendações de diversos autores favoráveis a cidades compactas, é necessário considerar primeiramente as características regionais. 0 reconhecimento de que a introdução ou a alteração de elementos na malha urbana são capazes de interferir na dinâmica das trocas térmicas e da ventilação marca a importância das especificidades do lugar na formação do microclima e no conforto ambiental (BARBOSA; DRACH; CORBELLA, 2010).

\section{Estudo de referência: Copacabana (RJ), Brasil}

Com a intenção de ilustrar a relação da morfologia com o clima local e pensar em projetos urbanos sustentáveis, esse artigo utilizou dados de temperatura e ventilação referentes ao bairro de Copacabana, na cidade do Rio de Janeiro. Tais dados são fruto de uma pesquisa paralela dos autores, que verificou alteração dos cursos de ventilação e sensível aumento da temperatura, a partir de simulações realizadas com maquetes do bairro submetidas a estudos no túnel de vento e com simulações computacionais, com o auxílio do software ENVI-met, desenvolvido para a realização de simulações climáticas em áreas urbanas.

Foram realizadas medições a partir de maquetes físicas e eletrônicas do arranjo físico de um trecho do bairro de Copacabana (entorno da Praça Serzedelo Correa) nas décadas de 1930, 1950 e 2010, utilizando dados da Prefeitura do Rio de Janeiro, através de plantas cadastrais e imagens. A partir dos resultados obtidos, buscou-se, neste artigo, apresentar possíveis causas e efeitos das mudanças morfológicas e tipológicas ocorridas em Copacabana. Além disso, avaliou-se se tais alterações de microclima sofridas por Copacabana podem ser mensuradas em outras localidades e se os métodos utilizados no estudo podem ser replicados para outros bairros que sofreram adensamentos.

\section{Breve histórico de Copacabana}

O bairro de Copacabana está localizado na Zona Sul da cidade do Rio de Janeiro, em latitude $22^{\circ} 54^{\prime} \mathrm{S}$ e longitude $43^{\circ} 12^{\prime}$ L. 0 bairro está situado na Área de Planejamento 2 (AP2), segundo a Divisão Administrativa Geral do Município do Rio, que engloba ainda o Leme (PREFEITURA DO RIO DE JANEIRO, 2013). Juntamente com outros bairros vizinhos, forma a chamada Zona Sul, considerada a região mais rica da cidade, mas com grave disparidade social.

A região sofreu uma urbanização tardia, em comparação com outros bairros, pois se encontrava em uma área de difícil acesso. Tratando-se de uma faixa estreita de terra rodeada por morros, até o fim do século XIX ainda era habitada apenas por pescadores. Somente com a construção de uma malha viária e a abertura do Túnel da Real Grandeza (atual Alaor Prata), o acesso ao bairro foi facilitado e a urbanização foi intensificada. No início do século XX, a Avenida Atlântica foi duplicada e edificações imponentes como o Hotel Copacabana Palace foram construídas, mas a maioria das delas ainda possuía, no máximo, três pavimentos.

Nas décadas seguintes o bairro se tornou boêmio, e com a existência de cassinos, confeitarias, teatros e bares, simbolizava a "modernidade" da elite carioca. Na década de 1940, a região sofreu acelerado crescimento populacional e uma consequente verticalização. Somente na década de 1970 foi alterado o dimensionamento da Avenida Atlântica e aterrada parte da praia, aumentando a faixa de areia. Até essa década, o gabarito das edificações era de 12 pavimentos, mas foi elevado para atender à demanda, principalmente, de hotéis da orla.

Em apenas dez anos, entre 1940 e 1950, a população quase dobrou no bairro, passando de 100 mil habitantes. É possível observar na Figura 1 a Copacabana da década de 1930, e na Figura 2, o mesmo bairro na década de 1950.

Nas décadas de 1980 a 2010, a verticalização continuou, mas as mudanças foram menos intensas com relação à década de 1950 . 0 interior do bairro também foi verticalizado e algumas ruas foram alargadas. A principal mudança foi vista na nova e ampliada Avenida Atlântica, na construção do famoso calçadão definido pelo paisagista Roberto Burle Marx e no aumento da faixa de areia, por meio de aterros feitos na década de 1970. 


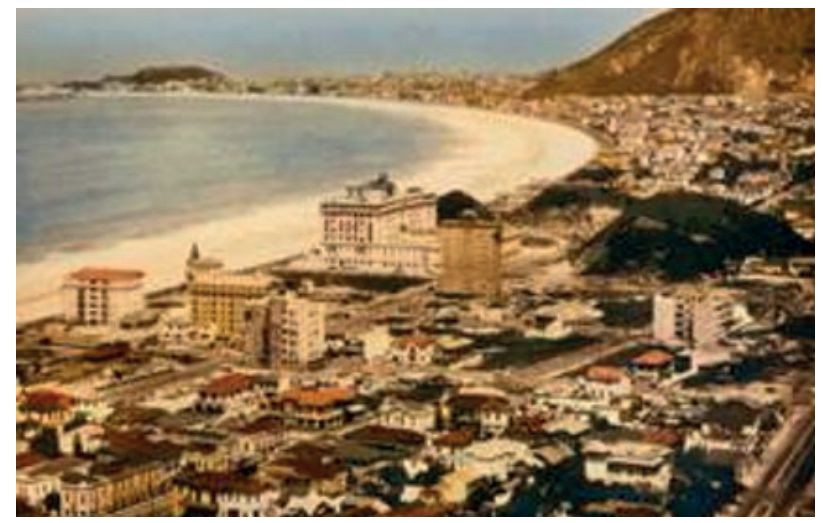

Figura 1 - Copacabana nos anos 1930

Fonte: VAZ, 2002.

Atualmente, Copacabana é um bairro considerado denso, tanto pela morfologia como pelo consequente número de habitantes. Possui cerca de 150 mil moradores e cerca de 65 mil domicílios em uma área de aproximadamente 410 ha (IBGE, 2010). A densidade de Copacabana não foi influenciada pelos estudos recentes sobre compacidade. 0 bairro passou por um processo de adensamento ainda em meados do século XIX. No entanto, esse adensamento seria considerado um fator positivo numa análise urbana com enfoque na sustentabilidade, caso esse bairro não estivesse localizado em uma região tropical.

Copacabana é um dos bairros mais conhecidos do Rio de Janeiro e possui um uso misto e variado, uma tipologia com diversos estilos e exemplares da década de 1920 a 2000, um gabarito quase regular, com edifícios variando, de maneira geral, entre 8 a 12 andares (Figura 3). Algumas exceções são as poucas casas remanescentes e algumas torres de hotel na orla do bairro.

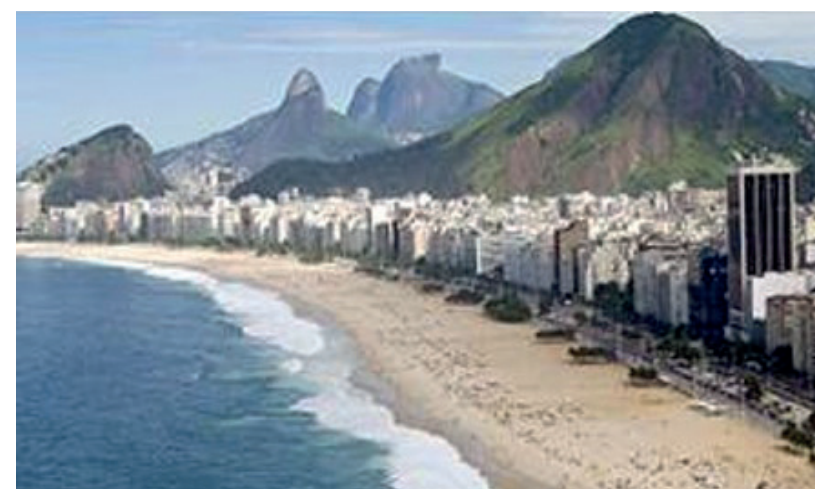

Figura 3 - Copacabana na atualidade (2013)

Fonte: PREFEITURA DA CIDADE DO RIO DE JANEIRO, 2013.

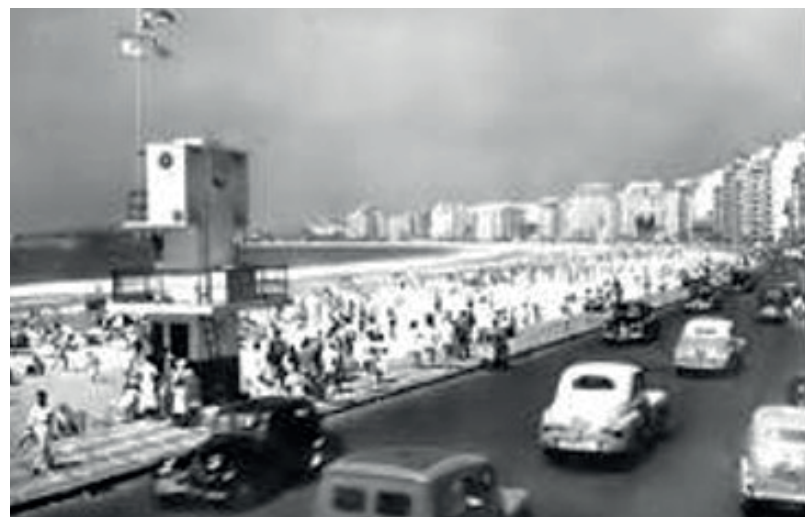

Figura 2 - Copacabana nos anos 1950

Fonte: SPREJER, 2012.

As vias são relativamente estreitas (cerca de 6 a $8 \mathrm{~m}$ de pistas de rolagem, com poucas exceções) e o bairro possui um desenho praticamente regular, com exceção das áreas de morro, em sua maioria ocupadas por habitações irregulares.

Suas vias principais, Avenida Atlântica e Nossa Senhora de Copacabana, são paralelas à praia e recebem o maior fluxo de veículos e pedestres (Figura 4). Por possuírem maior extensão, canalizam parte da ventilação, o que pode ser sentido até mesmo em uma caminhada pelo bairro.

\section{Estudo da relação entre a morfologia}

e o microclima de Copacabana

Como mencionado anteriormente, no decorrer dos anos, em Copacabana, houve significativo adensamento populacional, devido a uma grande especulação imobiliária e a uma legislação urbana que permitiu a compactação, tanto em Copacabana

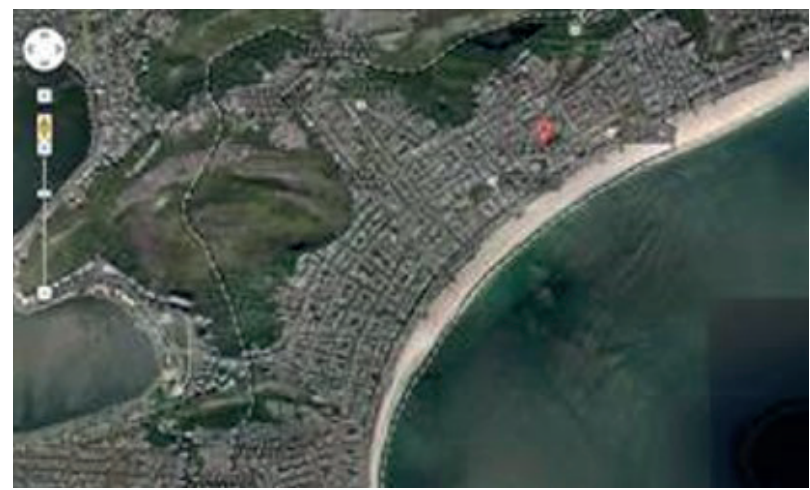

Figura 4 - Imagem aérea mostrando a delimitação do bairro de Copacabana Fonte: Imagem Aérea extraída do Google Earth, 2013. 
quanto na grande maioria dos bairros da Zona Sul carioca.

Não houve alteração significativa no desenho das vias do bairro, com exceção da orla, onde ocorreu o aumento da via principal a partir de um aterro em parte da praia, além do alargamento de algumas outras vias paralelas à orla. No entanto, os quarteirões foram tomados por edificações de alto gabarito e grande parte dos vazios foi preenchida. Além disso, alguns passeios foram estreitados para permitir melhor circulação de veículos, alterando, consequentemente, a morfologia do bairro (Figura $5 \mathrm{a}, \mathrm{b}$ e c).

De acordo com um estudo anterior realizado em um município vizinho ao Rio de Janeiro, a temperatura e a ventilação foram alteradas à medida que um de seus bairros sofreu adensamento (BARBOSA; DRACH; CORBELLA, 2010). A partir de simulação realizada com o programa ENVI-met, observaram-se diferenças de até $9{ }^{\circ} \mathrm{C}$ entre o bairro espraiado e o mesmo bairro compactado.
No caso de Copacabana, a alteração morfológica também pode ter contribuído para o aumento da temperatura. Tomando-se como exemplo a Praça Serzedelo Correa (Figura 6), no estudo da ventilação, ao considerar o vento sudeste (o mais relevante na área), a região da praça e principalmente as vias transversais à orla foram as que mais foram afetadas pela ventilação (DRACH; BARBOSA; CORBELLA, 2013). No entanto, no mês considerado para o estudo da temperatura (janeiro), a ventilação predominante era a leste; assim, as vias paralelas à orla foram as mais ventiladas e a praça sofreu menos intervenções. Consequentemente, as regiões mais ventiladas também são as mais frescas (Figura 7).

De acordo com os índices PET (Physiological Equivalent Temperature) e com o UTCI (Universal Thermal Climate Index), os valores medidos na região de Copacabana em janeiro mostram que a sensação térmica está na faixa de "extreme heat stress", principalmente na década de 2010.
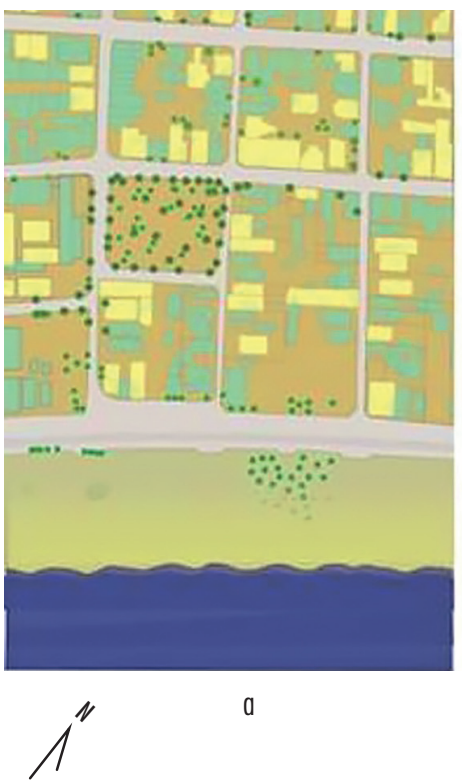

Legend:

Construction

- 106 meters

6 to 11 meters

12 to 15 meters

16 to 23 meters

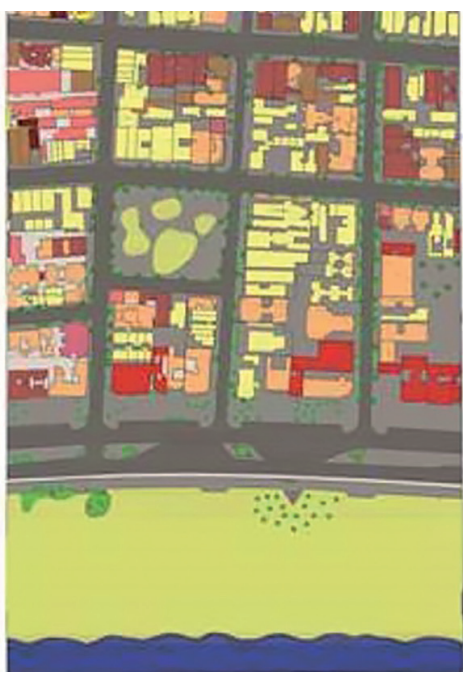

b

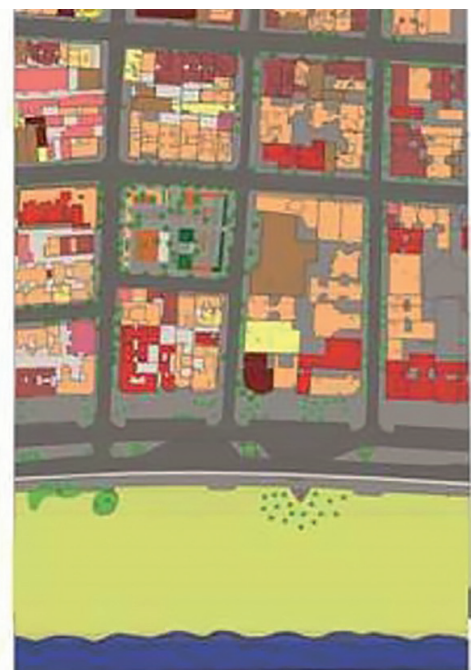

C

Green Area

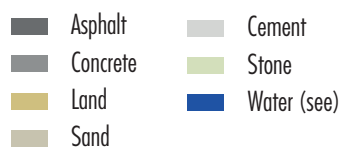

large trees

medium trees

- bush

grass

Figura 5 - Imagens da região estudada nas três épocas ( $a$ - 1930; b - 1950; c - 2010)

Fonte: Mapa desenvolvido pelas autoras. 
A Figura 8 (a, b e c) mostra as alterações de temperatura em um trecho do bairro no entorno da Praça Serzedelo Correa, nas décadas de 1930, 1950 e 2010․ É possível notar aumento da temperatura no interior do bairro, amenizado pelos ventos leste-sudeste. Além disso, é nítida a mudança da morfologia e das tipologias nas diferentes décadas e a

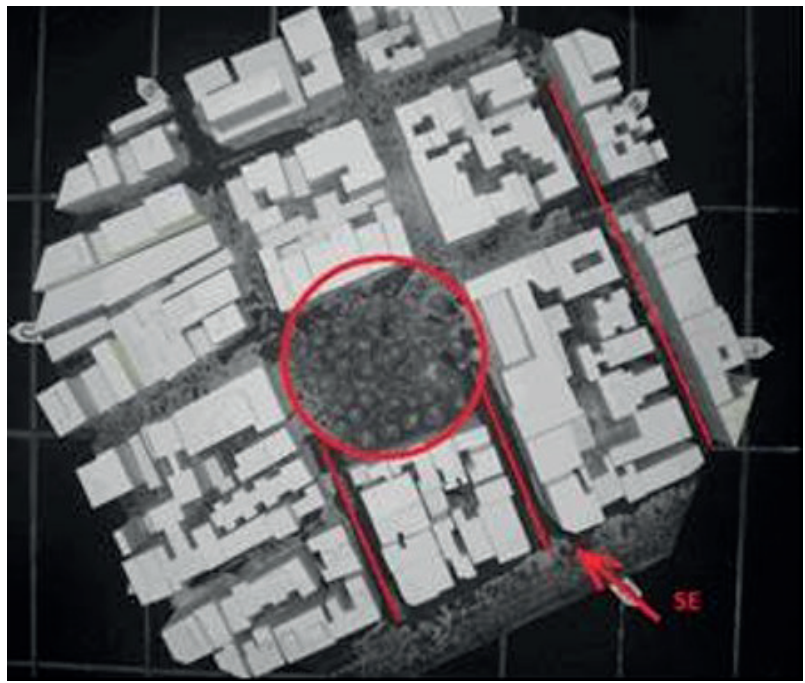

Figura 6 - Maquete mostrando a configuração da ventilação através de simulações do vento sudeste no Túnel de Vento Fonte: Imagem adaptada de DRACH; BARBOSA; CORBELLA, 2013. grande densidade dos dias atuais. Essas mudanças podem ser responsáveis pelo aumento da temperatura local, constatado no estudo citado.

Como o bairro está localizado em uma zona tropical, a densidade favorece o superaquecimento, aumentando a necessidade de condicionamento do ar, principalmente no verão. Esse quadro é agravado

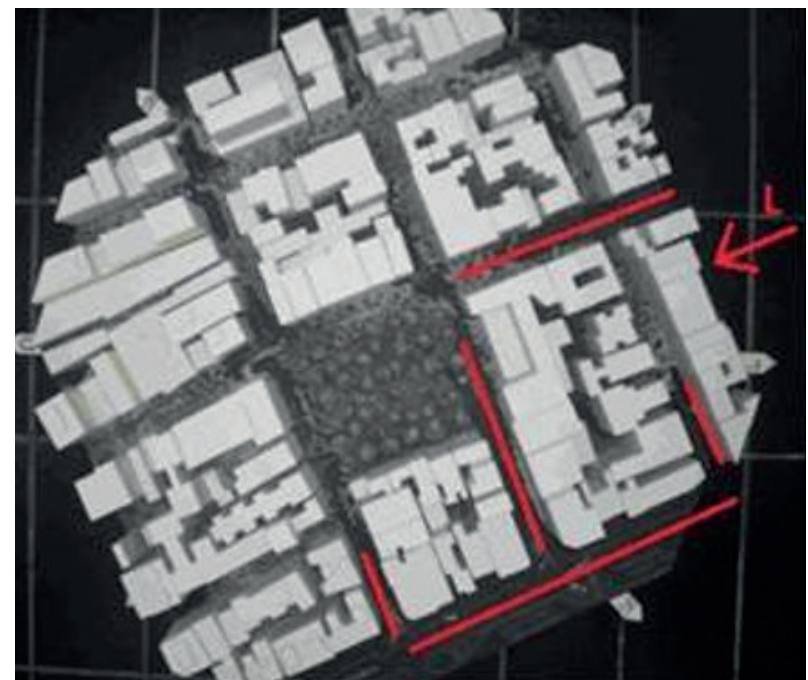

Figura 7 - Maquete mostrando a configuração da ventilação através de simulações do vento leste no Túnel de Vento Fonte: Imagem adaptada de DRACH; BARBOSA; CORBELLA, 2013.

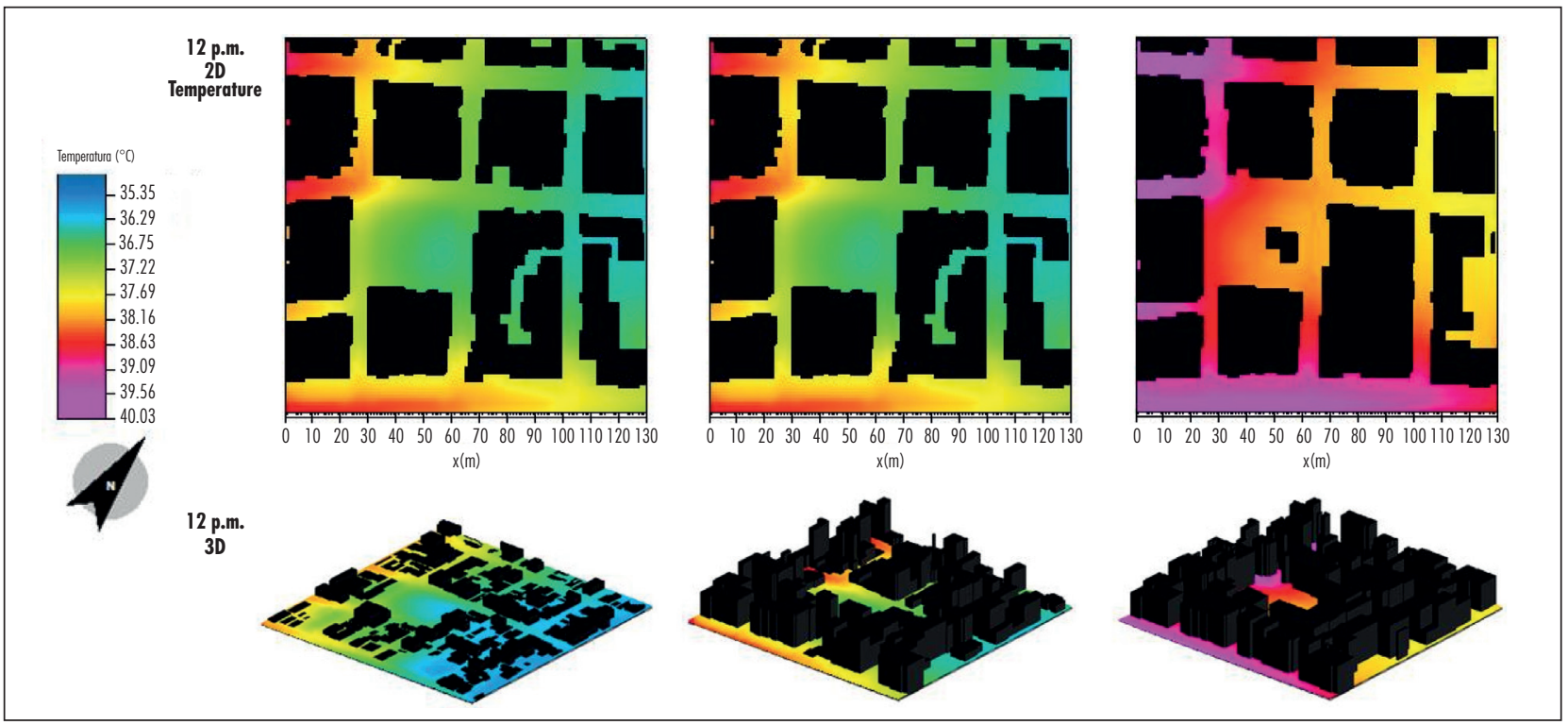

Figura 8 - Plantas do bairro de Copacabana nos anos de 1930, 1950 e 2010 e imagens em três dimensões das mesmas áreas Fonte: Dados da pesquisa. Gráficos obtidos pelo programa ENVI-met nas simulações de temperatura no mês de Janeiro, nas décadas de 1930, 1950 e 2010.

\footnotetext{
1 Dados obtidos com simulações no mês de janeiro, no horário de 12h, trabalhados no software ENVI-met e com simulações 3D realizadas no software Skechtup.
} 
pela falta ou pelo reduzido espaçamento lateral entre as edificações, o que forma uma barreira ao longo das vias para a permeabilidade, principalmente da brisa do mar. Ainda, é possível observar, na morfologia do bairro, que os quarteirões são maiores no sentido paralelo à praia, o que também dificulta a passagem dos ventos. Além disso, pelo fato de suas vias principais e mais largas estarem no sentido dos ventos predominantes (leste-sudeste), a velocidade do vento nelas é excessiva, agravada ainda pelo fluxo de veículos, enquanto nas vias perpendiculares a ventilação se torna escassa. Outro fator relevante que também pode ser considerado no aumento da temperatura local foi o aterro da praia, aumentando a faixa de areia e a Avenida Atlântica, distanciando a cidade da brisa do mar.

Além da morfologia e tipologia existentes, outros elementos contribuem para o aumento de temperatura na área em estudo. A grande área de impermeabilização do bairro e os revestimentos dos edifícios dificultam a dissipação do calor, devido à capacidade de armazenamento de calor desses materiais, associados à formação de barreiras à ventilação. Materiais como asfalto, concreto, vidro, telhas, dentre outros, ajudam na absorção do calor e favorecem o aumento da temperatura nas áreas urbanas. Dessa forma, o calor é dissipado principalmente durante a noite, o que faz com que a temperatura ainda se mantenha alta, mesmo no período noturno.

A proximidade dos edifícios, apesar de diminuir as distâncias entre as residências e o comércio, prejudica a iluminação natural e ainda torna a paisagem mais árida. Apesar de alguns estudiosos defenderem que o adensamento propicia maior sombreamento das edificações e que este contribuiria para a diminuição da temperatura, isso se torna praticamente imperceptível em áreas de clima tropical, onde a sombra não traz relativa alteração na temperatura (CORBELLA; YANNAS, 2003).

Muitas ruas são arborizadas, o que melhora a interação do bairro com o ambiente natural. Algumas praças, como a Serzedelo Correa, podem contribuir para a amenização da temperatura e a permeabilidade do solo. No entanto, os espaços naturais mais significativos do bairro (os morros reflorestados que o cercam) não foram integrados ao tecido urbano e possuem edifícios com grande gabarito em suas bases e áreas de favelas nos níveis subsequentes.

Todos esses fatores contribuem para a formação de ilhas de calor. A ilha de calor é mais comum nas zonas densas das cidades, como é o caso de Copacabana. As alterações térmicas podem ser de vários graus centígrados, ocorrem principalmente próximo ao solo (altura do pedestre) e podem ser causadas basicamente por diferenças de emissão de radiação infravermelha entre as regiões edificadas e não edificadas (CORBELLA; YANNAS, 2003) e agravadas pela canalização dos ventos e pela formação de barreiras.

Outro fator que favorece a formação de ilhas de calor é a presença de construções formadoras de barreiras urbanas, que, apesar de canalizar os ventos em ruas e avenidas, restringe a ventilação em determinadas áreas isoladas e cercadas pelas edificações ${ }^{2}$, como é o caso de Copacabana, principalmente na área da orla e na Avenida Nossa Senhora de Copacabana.

\section{Considerações finais}

As cidades são os locais onde grande parte da população escolheu viver e a inserção delas nas discussões sobre desenvolvimento sustentável demonstra a importância do tema. Acredita-se que alguns fatores podem contribuir para o ideal sustentável urbano, e talvez o mais visível deles seja o projeto urbano. A definição de um projeto e de uma legislação adequados pode garantir um bairro com melhor qualidade.

Inserida no tema do projeto urbano está a compreensão de que a forma, a infraestrutura, o modo de vida e a economia estejam integrados ao contexto local, considerando suas variáveis específicas ecológicas, sociais, culturais e econômicas. Dessa forma, o projeto é realizado para uma determinada região, população e época, podendo obedecer a princípios e metas gerais, mas com soluções específicas.

As soluções para os problemas urbanos não são óbvias nem simples, graças à complexidade de uma cidade e de todas as relações entre suas numerosas questões. 0 projeto urbano engloba seus arranjos físicos, sua necessidade de recursos e energia,

\footnotetext{
2 A velocidade do vento, algumas vezes, é maior em áreas urbanas em virtude do efeito de "cânions urbanos", e outras vezes, a velocidade diminui por causa das barreiras formadas por edificações uniformes (CORBELA; YANNAS, 2003).
} 
as produções de resíduos, as relações sociais e econômicas, dentre outras. Assim, na busca pela sustentabilidade urbana, o equilíbrio entre essas interações pode contribuir para a conservação de recursos e a redução dos resíduos. É importante salientar a necessidade de políticas públicas que colaborem para o equilíbrio econômico e social urbano.

A sustentabilidade passa por uma mudança comportamental e um posicionamento político, e apesar de necessitar alcançar muito além da forma urbana, são os espaços físicos que podem proporcionar a base material mais adequada para a realização das atividades urbanas de forma mais sustentável possível.

Nesse artigo, o termo sustentabilidade é compreendido como uma meta a ser alcançada e um processo para se chegar ao objetivo. Tal meta e processo se diferenciam de acordo com o contexto socioeconômico e ambiental de cada cidade. No caso de Copacabana, o projeto atual é resultado de uma série de intervenções e políticas urbanas que não tinham viés sustentável. 0 planejamento do bairro não previa uma morfologia adequada à ventilação e à iluminação. Além disso, o adensamento foi conduzido pela especulação imobiliária, o que resultou em um território árido e excessivamente adensado. No entanto, esse mesmo adensamento viabilizou a introdução de transporte público de massa como o metrô. Dessa forma, é possível notar que a sustentabilidade urbana não é uma matemática direta, mas o resultado de uma série de ações, intervenções e políticas públicas que podem propiciar ambientes urbanos mais saudáveis e com qualidade.

Considerando que as decisões de projeto da cidade relacionadas à forma influenciam diretamente nas alterações do microclima, este artigo tratou especificamente de morfologia urbana, analisando o caso das alterações morfológicas e climáticas ocorridas no bairro de Copacabana nas décadas de 1930, 1950 e 2010. Foram verificadas mudanças significativas no arranjo físico da área, no decorrer dos anos. 0 adensamento excessivo do bairro pode ter contribuído para a alteração do microclima local. Dessa forma, verifica-se que a densidade urbana, apesar de trazer aspectos positivos para a sustentabilidade, deve ser ponderada em países de clima tropical. 0 adensamento de edifícios e a praticamente total impermeabilização do bairro de Copacabana pode ser um dos fatores responsáveis pelo aumento de temperatura nas últimas décadas.
A localização do bairro de Copacabana favorece a ventilação, por estar em uma área de litoral. No entanto, diversos bairros em cidades brasileiras estão sendo adensados sem nenhum controle público ou, ainda pior, incentivados pelo poder público.

Após o estudo do bairro de Copacabana, foi possível observar que outros bairros que também sofreram adensamento abrupto, principalmente em regiões tropicais, como é o caso do Rio de Janeiro, também podem ter sofrido alteração do microclima. Dessa forma, afirma-se que a mesma metodologia de análise pode ser utilizada no estudo de outras localidades, ressaltando suas características locais. Além disso, as simulações podem ser feitas em projetos de bairros ainda em construção. Ainda, é possível utilizar esses parâmetros de análise para propor limitações de adensamento e de gabarito em bairros não compactos, mas que estão passando por processos de valorização e consequente adensamento. Esses tipos de simulações que relacionam a morfologia local ao clima podem ser ferramentas para gestores urbanos e servir como critério de avaliação de qualidade urbana.

Apesar de a cidade, ambiente construído, ser o habitat atual da humanidade, também se caracteriza como um dos principais agentes de intervenção no ambiente natural. Partindo do princípio de que o espaço urbano interfere nas relações humanas e no comportamento social, a busca pela sustentabilidade urbana pode ser reflexo de uma consciência ecológica despertada por diversos problemas ambientais. A definição de parâmetros de sustentabilidade auxilia nas intervenções urbanas mais adequadas ao local, considerando todas as regionalidades e especificidades. Conforme foi demonstrado, é relevante que a pesquisa científica avance nessa questão, com o propósito de fornecer resultados que auxiliem tanto nas decisões a serem tomadas quando da elaboração do projeto urbano quanto na elaboração de legislação urbanística e edilícia adequada ao contexto e clima locais.

\section{Referências}

ANDRA DE, L.; GOMES, V.; BORGES, M. The ecosystemic view of the urban occupation of Fernando de Noronha Island in Brasil. In: WORLD SUMMIT ECOCITY, 1., 2008, Fernando de Noronha. Anais eletrônicos... Fernando de Noronha, 2008. Disponível em: <http://www.globalislands.net/userfiles/_ brazil_FdNpdf6.pdf >. Acesso em: 21 jul. 2013. 
BARBOSA, G. 0 discurso da sustentabilidade expresso no projeto urbano. 2013. $310 \mathrm{f}$. Tese (Doutorado em Urbanismo) - Universidade Federal do Rio de Janeiro, Rio de Janeiro, 2013.

BARBOSA, G.; DRACH, P.; CORBELLA, O. A comparative study of sprawling and compact areas in hot and cold regions: way to sustainable development of cities. In: WORLD RENEWABLE ENERGY CONGRESS, 11., 2010, Abu Dhabi, Emirados Árabes. Proceedings... Abu Dhabi, 2010. CD-ROM.

BENTLEY, I. et al. Entornos vitales: hacia un diseño urbano y arquitectónico más humano - manual práctico. Barcelona: Gustavo Gili, 1999.

CERVERO, R.; KOCKELMAN, K. Travel demand and the 3Ds: density, diversity, and design. Transportation Research Part D: Transport and Enviroment, v. 2, n. 3, p. 199-219, 1997.

CORBELLA, O. Ciudades nuevas: clima y urbanismo. In: FORO LA NUEVA REALIDAD URBANA - METRÓPOLIS Y NUEVAS CIUDADES, 1., 1998, Buenos Aires. Anais... Buenos Aires, 1998. p. 80-88.

CORBELLA, O.; YANNAS, S. Em busca de uma arquitetura sustentável para os trópicos: conforto ambiental. Rio de Janeiro: Revan, 2003.

DEL RIO, V. Introdução ao desenho urbano no processo de planejamento. São Paulo: Pini, 1990.

DEL RIO, V.; SIEMBIEDA, W. (Org.). Desenho urbano contemporâneo no Brasil. Rio de Janeiro: LTC, 2013.

DRACH, P.; BARBOSA, G.; CORBELLA, O. Ventilation and urban morphology relation: two neighbourhoods in Rio de Janeiro City, Brazil. 2013. Trabalho apresentado ao PLEA, Munique, 2013.

FARR, D. Sustainable urbanism: urban design with nature. Hoboken: Wiley, 2008.

GIRARDET, H. Sustainables cities. Madrid: Editorial Celestial, 2001.

INSTITUTO BRASILEIRO DE GEOGRAFIA E ESTATÍSTICA — IBGE. Censo Demográfico - 2010. Rio de Janeiro: IBGE, 2010. Disponível em: <www.ibge.gov.br>. Acesso em: 15 ago. 2013.
JENKS, M.; DEMPSEY, N. Future forms and design for sustainable cities. Amsterdam; Boston: Architectural Press, 2005.

LEMOS, M. F R. C. Adaptação de cidades para mudança climática: uma metodologia de análise para os planos diretores municipais. 2010. 260 f. Tese (Doutorado em Urbanismo) - Universidade Federal do Rio de Janeiro, Rio de Janeiro, 2010.

MOORE, W. A. EcoDemocracia: el modelo postcapitalista. Buenos Aires: EMED; CEIS, 1998.

NOBRE, E. A. C. Desenho urbano: da teoria ao projeto. São Paulo: FAU/USP, 2004. 21 slides, color.

PREFEITURA DA CIDADE DO RIO DE JANEIRO. Copacabana na atualidade. Disponível em: <http:// www.rj.gov.br>. Acesso em: 17 ago. 2013.

RODRIGUES, F. de M. Desenho urbano: cabeça, campo e prancheta. São Paulo: Projeto, 1986.

ROSSI, G.; BARBOSA, G.; ARAGÃO, T. Sustainable neighborhoods and social housing urban projects: a comparison between Brazilian and European practices. In: IFME World Congress on Municipal Engineering, 2012, Helsinki. Proceedings... Helsinki, 2012.

SACHS, I. Desenvolvimento sustentável. Brasília: Instituto Brasileiro do Meio Ambiente e dos Recursos Naturais Renováveis, 1997.

SPREJER, P. Rio Antigo Social Clube. O Globo, 2012. Disponível em: <http://oglobo.globo.com/rio/rio-antigo-social-clube-6821923>. Acesso em: 21 jul. 2014.

VAZ, L. F. Modernidade e moradia: habitação coletiva no Rio de Janeiro — séculos XIX-XX. Rio de Janeiro: 7 Letras, 2002.

Recebido: $10 / 08 / 2013$

Received: 08/10/2013

Aprovado: $17 / 03 / 2014$

Approved: 03/17/2014 


\section{Errata}

No artigo "Análise de Projeto Urbano a partir de parâmetros urbanos sustentáveis: alteração morfológica de Copacabana e algumas de suas consequências climáticas (1930-1950-2010)", com número de DOI: 10.7213/ urbe.06.003.AC01, publicado no periódico Urbe - Revista Brasileira de Gestão Urbana, 6(3): 275-287, na página 284:

Onde se lia:

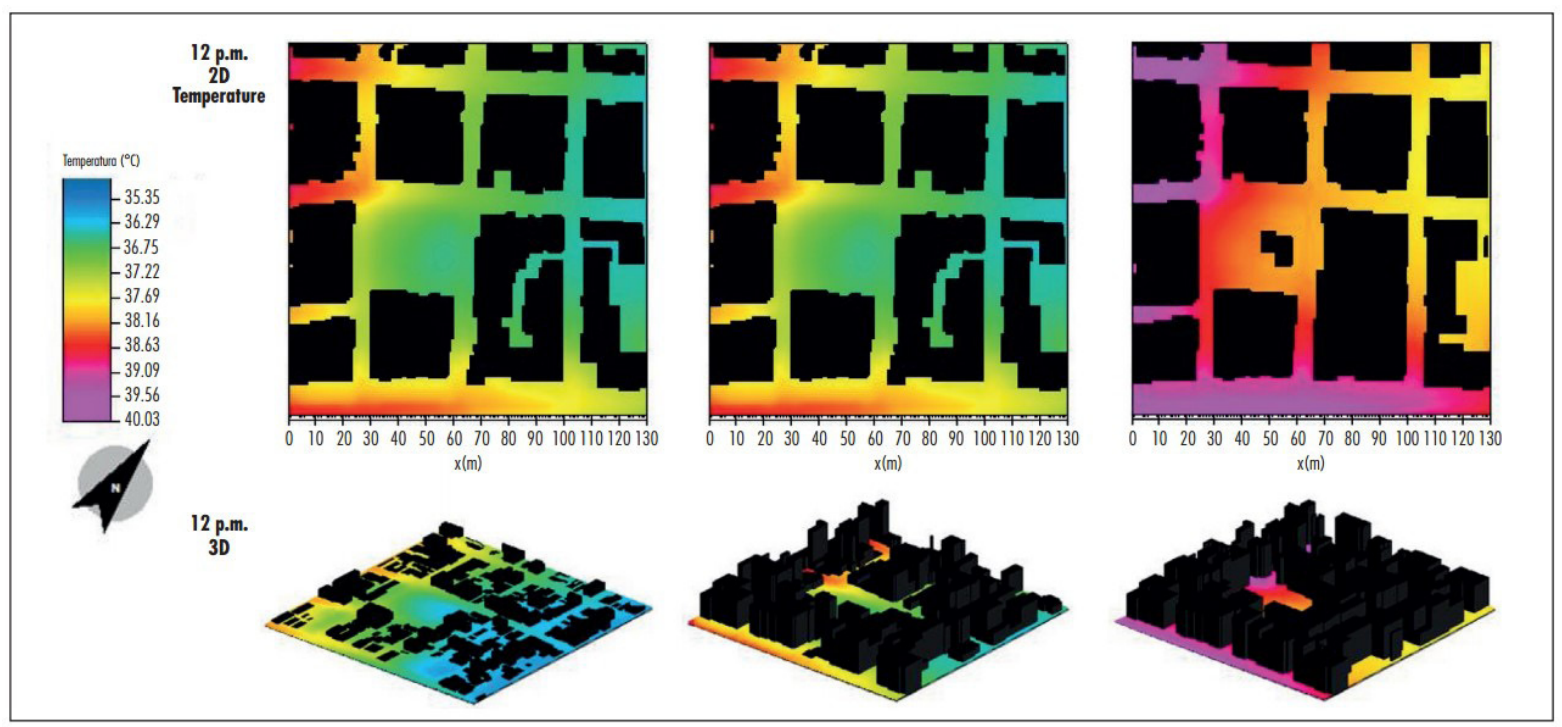

Figura 8 - Plantas do bairro de Copacabana nos anos de 1930, 1950 e 2010 e imagens em três dimensões das mesmas áreas Fonte: Dados da pesquisa. Gráficos obtidos pelo programa ENVI-met nas simulações de temperatura no mês de Janeiro, nas décadas de 1930, 1950 e 2010.

Leia-se:

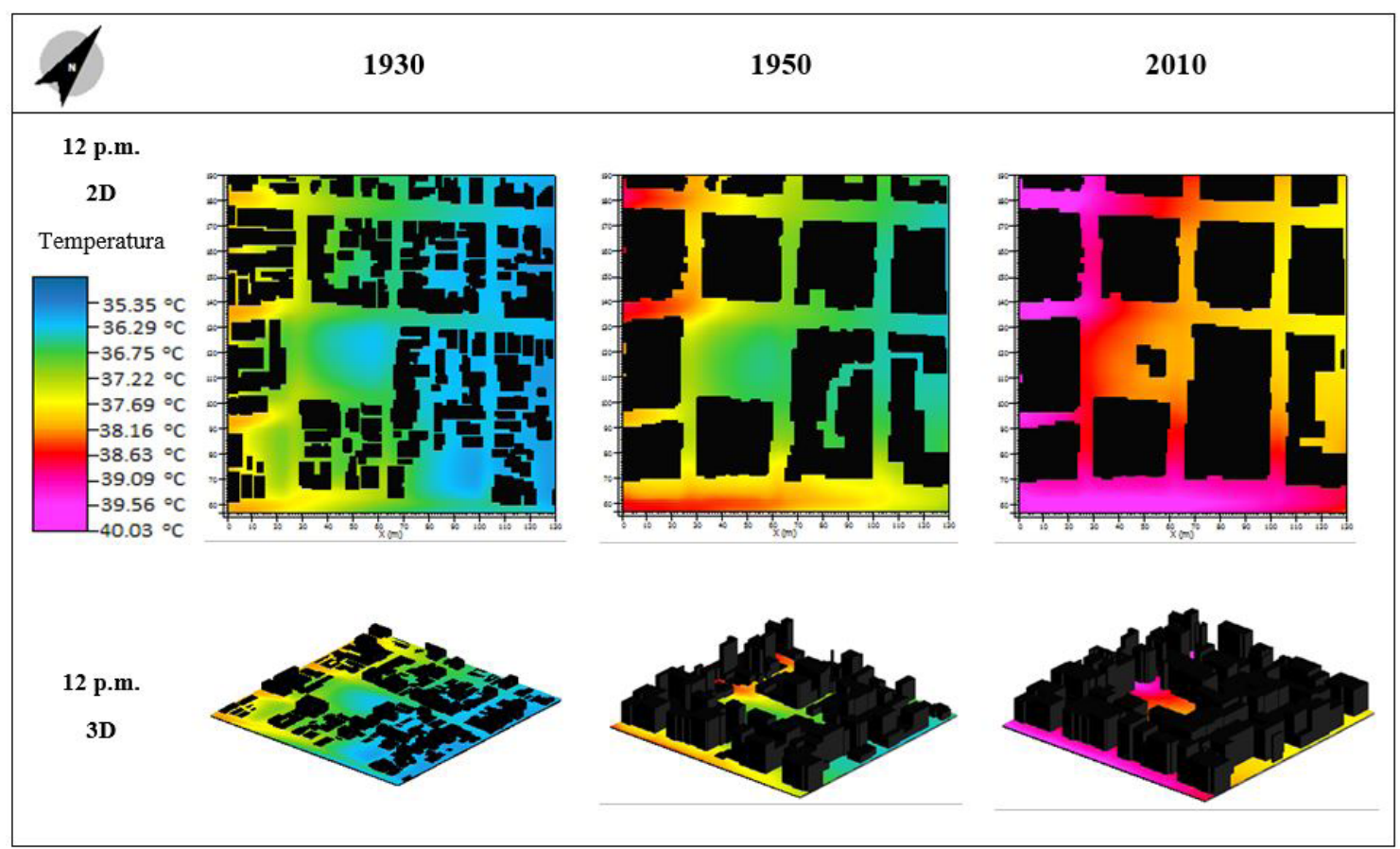

Figura 8 - Plantas do bairro de Copacabana nos anos de 1930, 1950 e 2010 e imagens em três dimensões das mesmas áreas Fonte: Dados da pesquisa. Gráficos obtidos pelo programa ENVI-met nas simulações de temperatura no mês de Janeiro, nas décadas de 1930, 1950 e 2010. 